\title{
Numerical simulation for apparent viscosity change under oscillating boundary condition using lattice Boltzmann method
}

\author{
Ryuta UEDA $^{1}$, Hitoshi MIKADA ${ }^{1}$, Tada-nori GOTO ${ }^{1}$ and Junichi TAKEKAWA ${ }^{1}$ \\ ${ }^{1}$ Dept. of Civil and Earth Res. Eng., Kyoto University
}

\begin{abstract}
Unsteady fluid dynamics in Newtonian and non-Newtonian fluid is the main concern of aeronautical, mechanical, chemical, resource, and civil engineering fields, etc. Seismic stimulation is known as one of the Enhanced Oil Recovery (EOR) methods and is regarded as one of unsteady flow problems. Numerous observations show that seismic stimulation to oil reservoir may improve oil production. However, for the application of seismic EOR efficiently, we need to understand the characteristics of changing apparent viscosity of fluid in geological formation. In this study, we attempt to demonstrate the apparent viscousity of fluid in laminar flow under oscillating boundary condition with the models of a single pore throat and porous media. In this study, we set up two hypotheses: one is pressure disturbance causes apparent viscosity change and the other is the apparent viscosity of porous media can be estimated in the use of apparent viscosity of single pore throats. Then, We find pressure disturbance causes apparent viscosity change as a function of the incident angle of shear waves in either vertical or horizontal and the tortuosity of pore throats. And we finally find that the change in the apparent viscosity for a network system of pores and pore throats could be different from that for a single pore throat model due to local pressure disturbance.
\end{abstract}

\section{INTRODUCTION}

Unsteady fluid dynamics in Newtonian and non-Newtonian fluid is the main concern of aeronautical engineering, mechanical engineering, chemical engineering, resource engineering and civil engineering. Since oil industry has a large problem: the amount of oil production in the world is decreasing recently, it is of importance to seek the technological development for enhanced oil recovery (EOR) in place in the subsurface. Seismic stimulation is known as one of the EOR methods. Recently, many laboratory experiments and field tests have been performed for water, gas, chemical, or thermal injections to attempt the enhancement of oil production. Also, numerous observations show that seismic stimulation of oil reservoir could improve oil production (Beresnev,1994; Robert et al.,2003). Some experiments and numerical simulations have been performed for understanding the causes of seismic EOR (Pride et al.,2005; Beresnev,2009). However we need to understand how the apparent viscosity under oscillating solid could vary. In this study, we attempt to demonstrate the apparent viscosity change in laminar flow under oscillating boundary condition with the models of a single pore throat and porous media.

In this study, we set up two hypotheses. First, the apparent viscosity for a single pore throat could change due to partial pressure disturbance caused by oscillation. Second, the change in the apparent viscosity would contribute to seismic EOR.

We use Lattice Boltzmann method (LBM) to simulate fluid flow in models of a single pore throat models and porous media with oscillating boundary condition. We calculate apparent viscosity change caused by wall oscillation and pressure disturbance.

\section{METHOD}

In this study, we use LBM described by Boltzmann equation (1).

$$
f_{i}^{n+1}=f_{i}^{n}-\frac{1}{\tau}\left(f_{i}^{n}-f_{i}^{n, e q}\right)
$$

We use 2-dimensional 9-velocity $(2 \mathrm{~d} 9 \mathrm{v})$ model to simulate 2-dimensional incompressible viscous flow (Fig.1). We assume that the background

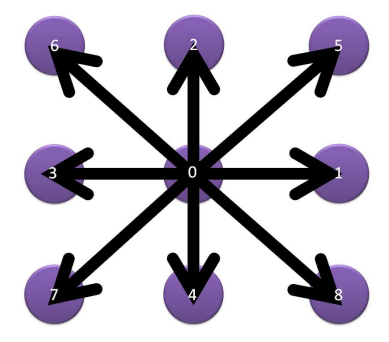

Fig.1 2d9v model 
pressure difference between inlet and outlet is we adopt bounce-back rule to satisfy with this condition (Fig.2). Flow is generated by a constant pressure difference.

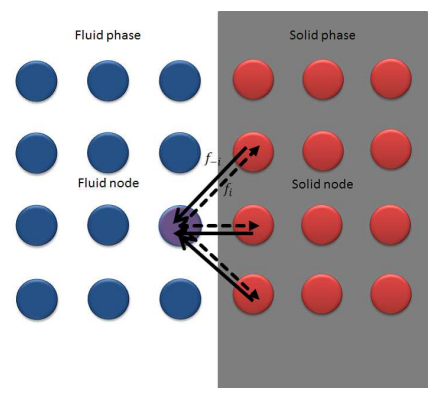

Fig.2 bounce-back rule

\section{SINGLE PORE THROAT MODEL}

\section{(1) Model}

Pore throats have complex shape. Choi and Clayton (2000) showed span-wise or stream-wise oscillation may improve flow. But, in laminar pipe flow, Clamen and Minton (1972) and Zaaem et al.(2008) showed stream-wise oscillation does not cause apparent viscos change. So, we simulate the flow in various pore shapes to grasp influences of those (Fig.3).

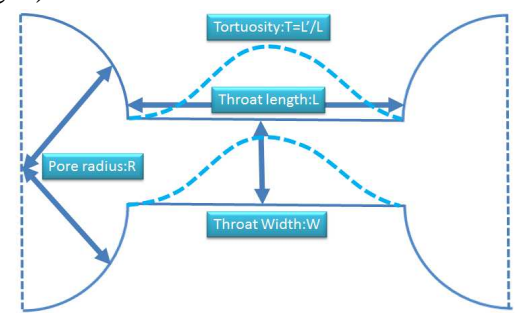

Figure. 3 Single pore throat model

\section{(2) Characteristics of incident wave}

First, we discuss four characteristics of an incident elastic wave: amplitude, frequency, angle, and pressure disturbance ( $\mathrm{P}$ wave). In these simulations, we assume the width of pore throat is $1.0 \times 10^{-4} \mathrm{~m}$, the length of that is $8.0 \times 10^{-4} \mathrm{~m}$, and the radius of pore is $2.0 \times 10^{-4} \mathrm{~m}$.

The characteristics of amplitude (Fig.4), frequency (Fig.5) and angle (Fig.6) are largely related with the amount of changing apparent viscosity. The flux increases under cases with large amplitude, high frequency, and large angle (S wave) or small angle ( $\mathrm{P}$ wave) of incident to the

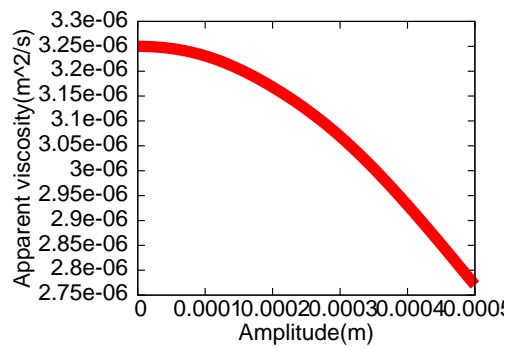

Figure.4 Amplitude characteristics

(Angle: Horizontal oscillation, frequency:250Hz) wall. High frequency and horizontal oscillation reduces viscosity resistance (Fig.4,5).

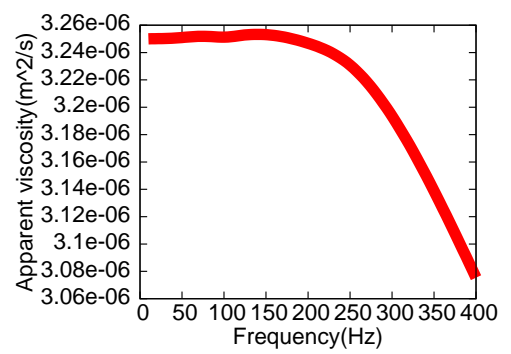

Fig.5 Frequency characteristics

(Angle: Horizontal oscillation, Amplitude:0.001m)

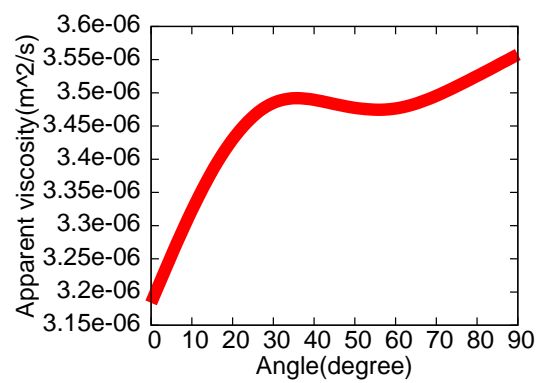

Fig.6 Characteristics of incident angle(S wave)

(Amplitude:0.001m, Frequency:250Hz)

On the contrary, pressure disturbance ( $\mathrm{P}$ wave) is not effective for changing apparent viscosity (Fig.7). To compare the effect of $\mathrm{P}$ wave with that of $\mathrm{S}$ wave, we assume same strain level and angle. Green line is apparent viscosity in $S$ wave propagation and red is that in $\mathrm{P}$ wave. $\mathrm{P}$ wave cause not only rock deformation without compression but fluid pressure disturbance directly. So, in the cases of same strain, $\mathrm{P}$ wave is larger for changing apparent viscosity than $\mathrm{S}$ wave. But $\mathrm{S}$ wave causes larger strain than $\mathrm{P}$ wave. So, the effect of $\mathrm{P}$ wave is not always more effective than that of $\mathrm{S}$ wave.

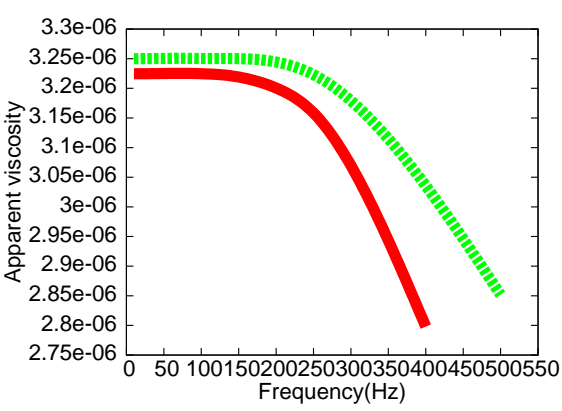

Fig.7 P wave characteristics

(Angle: Horizontal oscillation, Amplitude:0.0001m)

\section{(3) Characteristics of pore throat shape}

We examine pore throat length, width, pore radius, pore shape and tortuosity. All factors largely cause apparent viscos change. In this paper, we explain the characteristics of pore throat length and width due to limitation of space.

First, we compare the cases of various pore throat lengths and fix pore throat width $1.0 \times 10^{-4} \mathrm{~m}$, pore radius $2.0 \times 10^{-4} \mathrm{~m}$ and change width of a pore throat. 
Notes of Fig. 8 describe the details of pore throat lengths. In the case of long lengths and high frequency, apparent viscosity is flat or larger than in that of no oscillation (Fig.8). However, in short lengths and low frequency, we find apparent viscosity is smaller than in that of no oscillation.

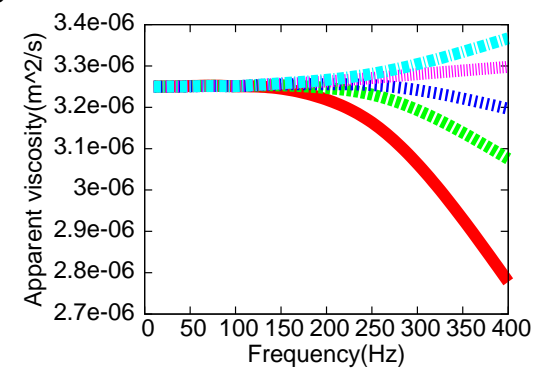

Fig. 8 Frequency characteristics of pore throat lengths (Horizontal oscillation, Red: $4.0 \times 10^{-4} \mathrm{~m}$, Green: $8.0 \times 10^{-4} \mathrm{~m}$, Blue: $1.2 \times 10^{-3} \mathrm{~m}$, Pink: $2.0 \times 10^{-3} \mathrm{~m}$, Light blue: $3.0 \times 10^{-3} \mathrm{~m}$ )

Then, we compare the cases of various pore throat widths and fix the length of pore throats, $8.0 \times 10^{-4} \mathrm{~m}$ and pore radius, $2.0 \times 10^{-4} \mathrm{~m}$. Notes of Fig. 9 describe the details of pore throat widths. In the case of narrow widths and high frequency oscillation (Purple and light blue), apparent viscosity is smaller than in that of not oscillating wall (Fig.9).

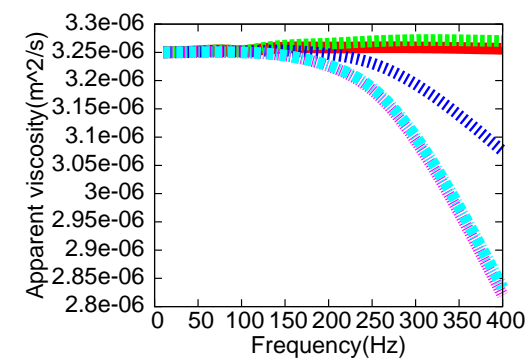

Fig.9 Frequency characteristics of pore throat widths (Horizontal oscillation, Red: $2.0 \times 10^{-4} \mathrm{~m}$, Green: $1.5 \times 10^{-4} \mathrm{~m}$, Blue: $1.0 \times 10^{-4} \mathrm{~m}$, Pink: $7.0 \times 10^{-5} \mathrm{~m}$, Light blue: $5.0 \times 10^{-5} \mathrm{~m}$ )

\section{(4) Discussion}

Our numerical results imply: i) the flow resistance increases because the velocity difference between the wall and the center of throat is larger than that in steady flow, ii) the effect of the advection term in oscillating wall is larger than that in steady flow (fig.9), iii) fluid extrusion is generated by partial pressure gradient, and iv) the oscillating wall may cause improving pressure loss.

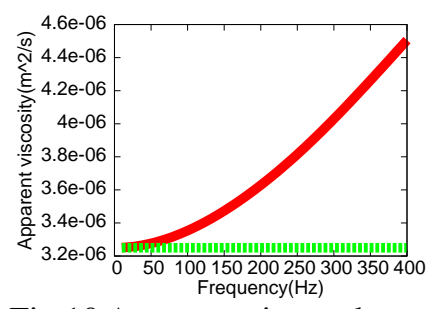

Fig.10 Apparent viscos change

(Red: considering advection term, Green: not considering)

Width: $1.0 \times 10^{-4} \mathrm{~m}$, length: $8.0 \times 10^{-4} \mathrm{~m}$, radius: $2.0 \times 10^{-4} \mathrm{~m}$

Amplitude: $1.0 \times 10^{-4} \mathrm{~m}$, Angle: Vertical oscillation.

\section{POROUS MEDIA MODEL (1) Model}

Next, we use simplified porous media model The model has $4 \times 4$ pore throats and $5 \times 5$ pores. For simplicity, in this model, we use same pores and throats. Then we compare the viscosity presumption using single pore throat model with apparent viscosity of porous model and discuss the influence of partial pressure disturbance.

\section{(2) Amplitude characteristics}

We compare the amplitude characteristics of pore throat length (Fig.11) and width (Fig.12). In the case of Fig.11, we fix pore throat width $1.0 \times 10^{-4} \mathrm{~m}$ and change lengths. Notes of Fig.11 describe details of the lengths. Also, in the case of Fig.12, we fix pore throat length $8.0 \times 10^{-4} \mathrm{~m}$ and change widths. Notes of Fig. 12 describe the details of pore throat width. In the case of short length, wide width of pore throats, we can get large apparent viscosity reduction. On the other hand, in the case of long length and narrow width of pore throats, we find apparent viscosity reduction.

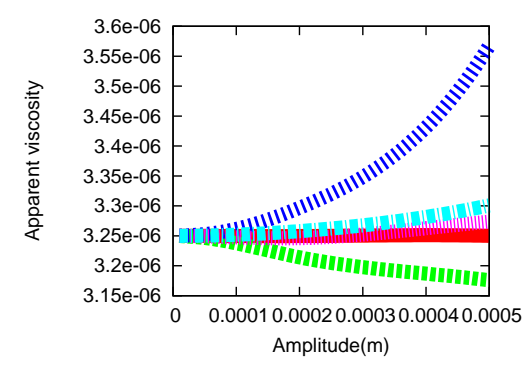

Fig.11 Amplitude characteristics of pore throat length $\left(100 \mathrm{~Hz}\right.$, Horizontal oscillation, Red: $8.0 \times 10^{-4} \mathrm{~m}$,

Green: $4.0 \times 10^{-4} \mathrm{~m}$,Blue: $2.0 \times 10^{-3} \mathrm{~m}$, Sky blue: $1.5 \times 10^{-3} \mathrm{~m}$ )

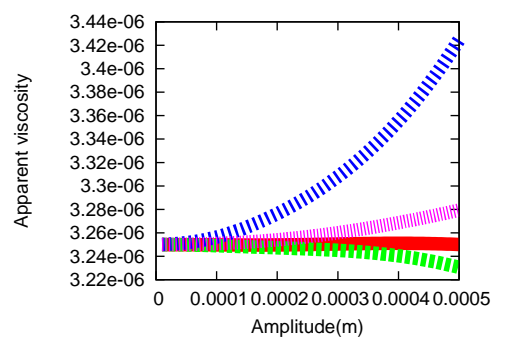

Fig.12 Amplitude characteristics of pore throat widths

$\left(100 \mathrm{~Hz}\right.$, Horizontal oscillation, Red: $1.0 \times 10^{-4} \mathrm{~m}$,

Green: $2.0 \times 10^{-4} \mathrm{~m}$, Blue: $5.0 \times 10^{-5} \mathrm{~m}$, Purple: $7.0 \times 10^{-5} \mathrm{~m}$ )

\section{(3) Frequency characteristics}

We compare the amplitude characteristics of pore throat length (Fig.13) and width (Fig.14). The conditions of Fig.11 and Fig.13 are same. Also, the conditions of Fig.12 and Fig.14 are same. In the case of short length and wide width of a pore throat and high frequency, we can get large apparent viscosity reduction. On the other hand, in the case of long length and narrow width of pore throats, we can find apparent viscosity reduction. 


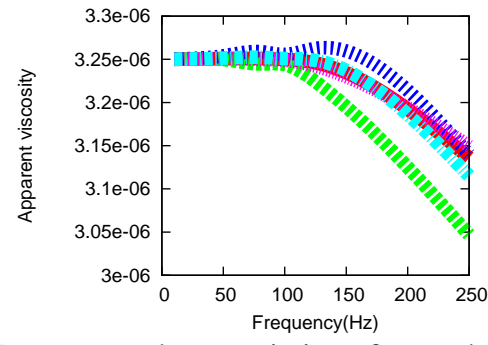

Fig.14 Frequency characteristics of pore throat width (Amplitude: $0.0001 \mathrm{~m}$, Horizontal oscillation, Red: $1.0 \times 10^{-4} \mathrm{~m}$, Green: $2.0 \times 10^{-4} \mathrm{~m}$,Blue: $5.0 \times 10^{-5} \mathrm{~m}$, Purple: $7.0 \times 10^{-5} \mathrm{~m}$ )

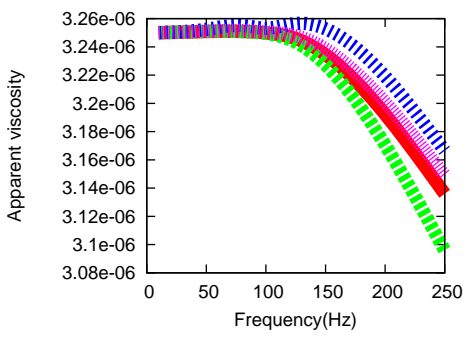

Fig.15 Frequency characteristics of pore throat length

(Amplitude: $0.0001 \mathrm{~m}$, Horizontal oscillation, Red: $8.0 \times 10^{-4} \mathrm{~m}$, Green: $4.0 \times 10^{-4} \mathrm{~m}$,Blue: $2.0 \times 10^{-3} \mathrm{~m}$, Sky blue: $1.5 \times 10^{-3} \mathrm{~m}$ )

\section{(4) Discussion}

We compare the viscosity presumption using single pore throat model with apparent viscosity of porous media model. We fix pore throat length $8.0 \times 10^{-4} \mathrm{~m}$ and pore radius $2.0 \times 10^{-4} \mathrm{~m}$ and compare narrow throat model and wide one. In narrow one, the presumptions are very similar to apparent viscosity of porous media (Fig.16). In constant, in wide one, we can find the presumptions are different from apparent viscosity (Fig.17).

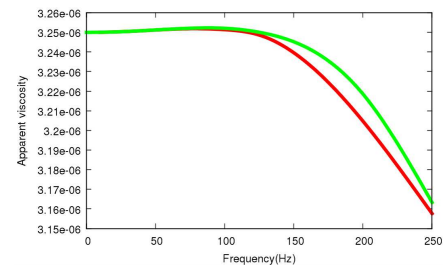

Fig.16 Comparison in narrow pore throat model (Width: $5.0 \times 10^{-5} \mathrm{~m}$ )

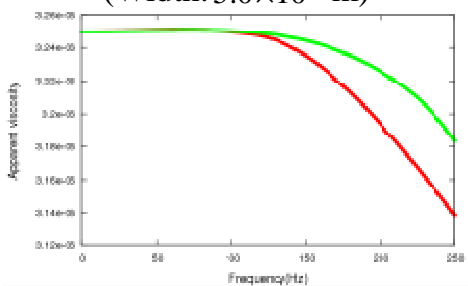

Fig.17 Comparison in wide pore throat model (Width: $1.0 \times 10^{-4} \mathrm{~m}$ )

We examine the velocity and pressure average during one period of oscillation (Fig.18). The colors of contour mean pressure: red is high pressure and blue is low pressure. The vectors mean flow velocity. We find not only partial pressure disturbance in a single pore throat but that over pore throats are effective for changing apparent viscosity.

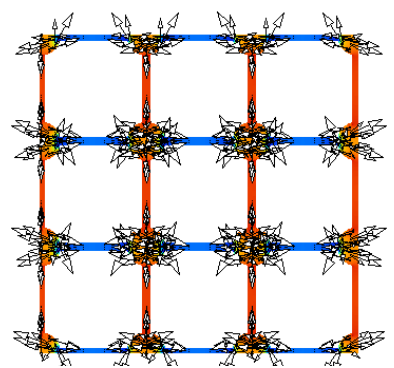

Fig.18 Pressure and velocity distribution (Horizontal oscillation, Frequency: $100 \mathrm{~Hz}$, Amplitude:0.0001m)

\section{CONCLUSION}

In this study, we tested two hypotheses: one is pressure disturbance causes apparent viscosity change, and the other is that the apparent viscosity change would contribute to seismic EOR.

We find pressure disturbance causes apparent viscos change and that horizontal oscillation could reduce the apparent viscosity for a horizontally laid pore throat while the vertical oscillation show the opposite effect. We compare the viscosity presumption using single pore throat model with apparent viscosity of porous media model and find not only partial pressure disturbance in single pore throat but that over pore throats are effective for changing apparent viscosity.

\section{REFERENCES}

1) Beresnev, I.A. and Paul A. J. (1994) Elastic-wave stimulation of oil production: A review and results, Los Alamos National Laboratory, Geophysics, 59, 6, 1000-1017.

2) Beresnev, I.A, (2009) Viscosity effect in vibratory mobilization of residual oil, Geophysics, 75, 4, N79-N85

3) Clamen, M. and Minton, P., (1976) An experimental investigation of flow in an oscillating, J. Fluid Mech., 81, 421-431.

4) Choi, K. and Clayton, R. B., (2000) The mechanism of turbulent drag reduction with wall oscillation, Int. J. of Heat and Fluid Flow, 22, 1-9

5) Pride, S.R., Flekkoy, E. and Aursjo, O., (2008) Seismic stimulation for enhanced oil recovery, Geophysics, 73, O23-P35.

6) Robert, P. M.., Esipov, I. B., and Maier, E. L.(2003), Elastic wave stimulation of oil reservoirs:Promising EOR technology?,Leading Edge May 2003, 448-453

7) Zaaem, M.A., Lapin, S., Matveev, K., (2009) The Effect of Vibration on Flow Rate of Non-Newtonian Fluid, Proc. Fourth SIAM Conference on Math. for Industry, 137-141 